\title{
A Web Based Digital Repository for Scholarly Publication
}

\author{
Raymond Okon, Ebele Leticia Eleberi, Kanayo Kizito Uka \\ Department of Computer Science, Imo State University, Owerri, Nigeria \\ Email: ekwonwuneemmanuel@yahoo.com
}

How to cite this paper: Okon, R., Eleberi, E.L. and Uka, K.K. (2020) A Web Based Digital Repository for Scholarly Publication. Journal of Software Engineering and Applications, 13, 67-75. https://doi.org/10.4236/jsea.2020.134005

Received: April 28, 2019

Accepted: April 6, 2020

Published: April 9, 2020

Copyright $\odot 2020$ by author(s) and Scientific Research Publishing Inc. This work is licensed under the Creative Commons Attribution International License (CC BY 4.0).

http://creativecommons.org/licenses/by/4.0/

(c) (i) Open Access

\begin{abstract}
Institutional repositories are essential research infrastructure for research-based universities. A properly dimensioned institutional repository has the potential to increase research impact and enhance the visibility of an institution through its scholarly outputs. The aim of the study is to design and develop a web-based digital repository for scholarly materials and publications in a tertiary institution. The motivation for carrying out this project is to provide a lasting solution to the need for an effective, efficient, reliable and easily accessible system for storing and retrieving scholarly materials, which will make study and research work less cumbersome and stressful for academic staff and students, thereby enabling them to easily carry out their day-to-day activities, especially as it concerns obtaining relevant scholarly information quickly. The system will be developed using open source software and OOADM (Object Oriented Analysis and Design Methodology). Findings obtained from system validation tests show that the system is a viable solution to the major challenges encountered in the management and sharing of scholarly information at the institution.
\end{abstract}

\section{Keywords}

Web-Based, Digital Repository, Multimedia, Publication, Internet Protocol

\section{Introduction}

An institutional repository (IR) is a system that collects, preserves, manages, and provides access to intellectual products of a community [1]. Institutional intellectual products may include faculty work, student theses and dissertations, e-journals, datasets, and so on. IRs provide a mechanism for an institution to showcase its scholarly output, centralize and introduce efficiencies to the stewardship of digital documents of value, and respond proactively to the escalating 
crisis in scholarly communication [2]. The availability of open-source repository systems has encouraged and led to the proliferation of IRs worldwide, particularly among academic and research institutions.

Building a comprehensive web based digital repository system will help users to manage all phases of the information lifecycle, and most importantly, to simplify the authoring and creation process so that wider population can participate by adding different types of multimedia content directly into the digital repository/library. Downstream access allows readers to benefit from this type of digital, web-based communication, across time and space. Ultimately, it is believed that knowledge will be made more readily and easily available, which will lead to yet another cycle of discovery, authoring and utilization.

\subsection{Literature Review}

The growing trend towards online scholarly communication and lack of scholarly content management systems among universities has made digital repositories more important for the collection and distribution of scholarly materials [3] [4] [5]. Today, digital repositories are used at academic institutions to store and disseminate scholarly outputs of universities [5].

In a general sense, an "institutional repository" can mean many things; a library, an archive, a museum, or even a warehouse that stores an organization's records or artifacts for use and safekeeping all fall under the broad definition of institutional repository. In recent years, however, an IR has taken on a more specific, but still evolving meaning that refers to the storage and preservation of an organization's digital information or knowledge assets.

It is a set of services offered by a university to its community members for the stewardship of scholarly publication generated by the faculty, staff, and research scholars by preserving it for long term. Since the resources are generated digitally and electronically, it is very easy to build a collection of any specific subject discipline or any targeted user group.

An Institutional Repository consists of formally organized and managed collections of digital content generated by faculty, staff and students at an institution. This is the collective intellectual output of an institution, recorded in a form that can be preserved and exploited. IR helps institutions to collect, secure and provide access to scholarly publication in a novel, digital way, mostly initiated by the institutional library. Institutional repositories are spreading, as they have become an indispensable component for information and knowledge sharing in the scholarly world.

An institutional repository is an archive for collecting, preserving, and disseminating digital copies of the intellectual output of an institution, particularly a research institution [6] [7] [8] [9]. Within the specific context of academia, an Institutional Repository may contribute to the increase of the institution prestige as it showcases the institutions scholarly accomplishments, whilst managing and preserving relevant informational items that otherwise would remain scattered, unattended or inaccessible. 
An institutional repository can be viewed as a "...a set of services that a university offers to members of its community for the management and dissemination of digital materials created by the institution and its community members" [10]. For a university, this includes materials such as monographs, eprints of academic journal articles-both before (preprints) and after (postprints) undergoing peer review-as well as electronic theses and dissertations. An institutional repository might also include other digital assets generated by academics, such as datasets, administrative documents, course notes, learning objects, or conference proceedings. Deposit of material in an institutional repository is sometimes mandated by that institution.

Some of the main objectives for having an institutional repository are to provide open access to institutional research output by self-archiving in an open access repository, to create global visibility for an institution's scholarly research, and to store and preserve other institutional digital assets, including unpublished or otherwise easily lost ("grey") literature such as theses, working papers or technical reports.

\subsection{Motivation}

Times are fast changing; we now live in a jet age which is mainly characterized by rapid changes in technology, lifestyle and value. This is indeed an age of information explosion.

Two of the major inventions that have driven the world to a fast pace of technological advancement are the computer and the internet. The computer is primarily an electronic information processor that is rapidly changing the way we acquire, organize, recall, access, analyze, synthesize and apply information. The Internet is a worldwide system of interconnected computer networks designed to use the standard Internet Protocol Suite (TCP/IP), that is available to everyone. The effectiveness with which the information is generated and communicated determines the rate of progress of a society and the fulfillment of its people. Modern society is information driven and information today is a universal need.

Moreover, computers and the internet have affected the ways which people use information. It has changed the rate of work done, the method for accomplishing the work alongside the relationship among the people carrying and using the information. However, despite the tremendous growth in Information Technology over the years, most tertiary institutions are yet to take advantage the growing trend to improve their process of storing and obtaining information. The motivation for carrying out this project is to provide a lasting solution to the need for an effective, efficient, reliable and easily accessible system for storing and retrieving scholarly materials, which will make study and research work less cumbersome and stressful for academic staff and students, thereby enabling them to easily carry out their day-to-day activities, especially as it concerns obtaining relevant scholarly information quickly. 


\subsection{Statement of the Problem}

There are numerous problems with the traditional system of storing scholarly materials in tertiary institutions. These in-adequacies are enumerated below.

1) The users who require access to these materials need to go the library or offices physically which most times could lead to congestion?

2) Inability for the academic resources to be accessed $24 / 7$.

3) The academic resources cannot be simultaneously used. It is one at a time.

4) Traditional storage is limited by storage space.

5) Degradation of hard copy scholarly materials from repeated use.

6) High cost, stress and time wasted in publishing on external journal repositories.

The implementation of a web-based digital repository for scholarly materials and publications will help curb the problems listed above by providing an efficient and reliable solution for prompt uploading, storing and retrieval of the institution's scholarly materials. Also, being web-based means that you can have several users accessing the repository and archived materials simultaneously at the same time.

\subsection{Aim and Objectives}

The aim of this project is to develop a functional web-based digital repository for scholarly publications and materials using Dspace repository software, to make access to academic resources and materials from within or outside the institution easy and efficient. The objectives to actualize this aim are listed below:

1) To develop a digital system that supersedes the operations of the present manual system of storing scholarly materials in hard copy, which is both stressful and expensive to maintain.

2) To organize and index digital documents for different purposes using a system that is user friendly, thereby making it easy and convenient for the users to retrieve needed information quickly.

3) To develop a highly efficient system with comprehensive storage capacity for a large repository of data that can be accessed by authorized users.

4) To develop a system that can be used for publishing digital journals, thereby reducing the cost, stress and time wasted in publishing on external journal repositories.

\subsection{Significance of Study}

The implementation of a web-based digital repository for scholarly materials and publications will improve the current manual system of storing documents in hard copy. The following are other importance of the proposed system:

- Removal of Physical Boundaries: Providing open access to research outputs of institutions to a worldwide audience both within and outside the institution.

- Resource Maximization: Maximizing the impact and enhancing the visibility of the scholarly works produced at the institution. 
- Easy Institutional Performance Assessment: And managing and measuring the impacts of institutional research and teaching activities.

- Round the Clock Availability: To enable users to be able to gain 24/7 access to the information.

- Easy Information Retrieval: To make it easy and convenient for the user to retrieve needed information quickly.

- Preservation and Conservation: Provide access to materials that would otherwise fall to degradation from repeated use.

- Multiple Access: Ensure that the same resources can be used simultaneously by a number of persons.

- Space: Able to provide storage for information digitally by using little physical space to contain them.

\section{Methodology}

In order to determine whether or not a web-based digital repository system for IMSU is feasible, there must be some form of investigation into the goals and implications of the project. For very small-scale projects this may not be necessary at all as the scope of the project is easily understood. In larger projects, the feasibility may be done but in an informal sense, either because there is no time for a formal study or because the project is a necessity and will have to be done one way or the other. Inevitably this report is a different document from the study itself for reasons of easy readability. By synthetically pointing out the main principles case by case it allows one to constantly refer to the various sections of the study itself; hence it may, because of its very structure, be used as an intelligent index to the digital library document in its complex whole. When a feasibility study is carried out, there are four main areas of consideration:

- Technical-is the project technically possible?

- Financial-can the business afford to carry out the project?

- Organizational-will the new system be compatible with existing practices?

- Ethical-is the impact of the new system socially acceptable?

To answer these questions, the feasibility study is effectively a condensed version of a fully-blown systems analysis and design. The requirements and users are analyzed to some extent, some business options are drawn up and even some details of the technical implementation.

A research methodology is a systematical programming approach of a well-defined procedure that should be followed in caring out a thorough research work. In other to attain quiet a reasonable acceptance of the research work we made use of the internationally accepted software engineering model, which is OOADM (Object Oriented Analysis and Design Methodology).

\section{Object Oriented Analysis and Design Methodology (OOADM)}

Most developers are familiar with the concepts of object-oriented development, yet those same ideas begin from a more extensive way to deal with the whole 
software development life cycle known as object-oriented analysis and design (OOAD). As shown in Figure 1, OOAD is a specialized technique for analyzing and designing an application dependent on that system's object models (the logical components of the system that interact with each other).

\section{Object-Oriented Analysis}

Before defining object-oriented analysis, we should initially define an object. According to most dictionaries, an object is "a substantial, material thing." Drilling down more to the domain of software engineering, an object can be most anything in a program sense, from a variable or data model to a function, class, or method. Moving considerably more profound into the domain of object-oriented programming, an object is an instance of a thing that normally represents a certifiable object and has all similar qualities (properties), behaviours (methods), and states (data). While talking about OOAD concepts, an object most intently looks like the object-oriented programming rendition of an object, in that it is a portrayal of a real-world object with behaviours, attributes, and states.

With that being said, we can now define object-oriented analysis (OOA). To put it plainly, OOA is an iterative phase of analysis, which happens amid the program development life cycle, that aims to model the functional prerequisites of the software while remaining totally free of any potential execution requirements. To achieve this task by means of OOAD practices, an object-oriented analysis will center everything through the perspective of objects. This causes OOA to consolidate all behaviours, attributes, and states together into one analysis process, as opposed to splitting them up into independent stages, like most other methodologies would do.

To actualize this goal, a typical OOA phase is made up of five stages:

- Locate and define the objects.

- Organize the objects.

- Describe how the objects relate with each another.

- Define the external behavior of the objects.

- Define the internal behavior of the objects.

For instance, a typical execution of OOA is to make an object model for an application. The object model may portray the names, relationships, behaviors, and attributes of each object in the system. With this data set up for each object,

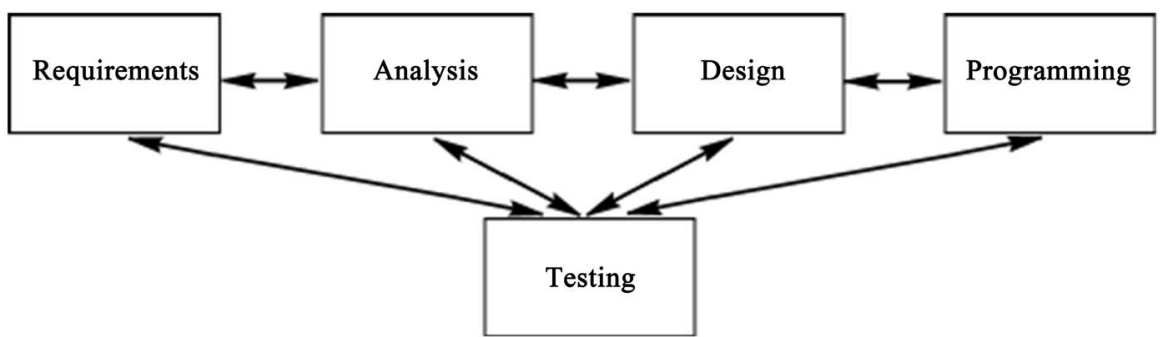

Figure 1. A minimal OOADM software development process (Image Source: https://www.ibm.com/developerworks/library/ws-using-oo). 
the design process that follows is a lot less complex. Figure 2 shows an overview of Object-Oriented Analysis artifacts and their relationships.

\section{Object-Oriented Design}

The procedure of object-oriented design is actually only an expansion of the object-oriented analysis process that preceded it, except with a critical caveat: the consideration and execution of constraints. For instance, with an analysed object available, for example, an object model, we should now think about how that object would really be designed and executed, which will frequently require the use of constraints, for example, hardware or software platforms, time and budgetary constraints, execution requirements, engineer fitness, etc. At the end of the day, the OOD procedure takes the hypothetical ideas and thoughts arranged during the OOA stage, and endeavors to figure out how to design and substantially execute them, usually by means of code, utilizing whatever language and platforms the development group has settled upon. OOA is the what, while OOD is the how. Figure 3 illustrates an overview of Object-Oriented Design artifacts and their relationships.

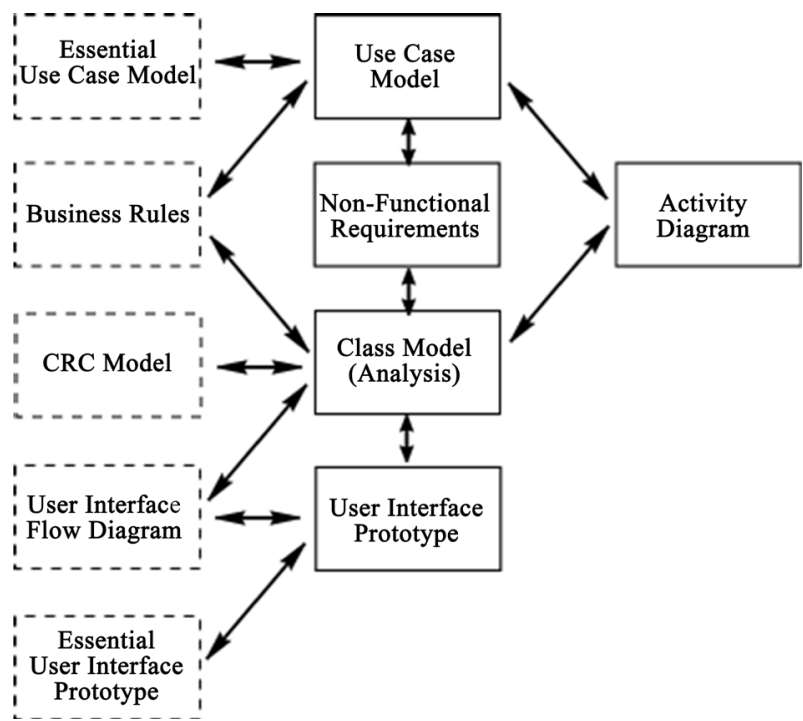

Figure 2. Overview of analysis artifacts and their relationships (Image Source: https://www.ibm.com/developerworks/library/ws-using-oo).

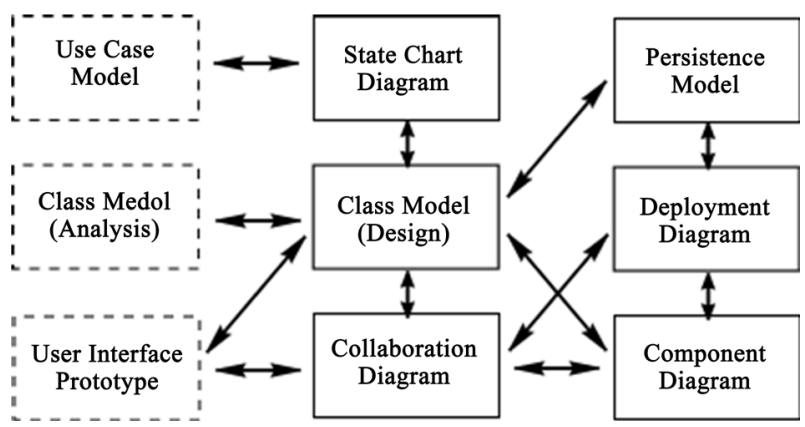

Figure 3. Overview of design artifacts and their relationships (Image Source: https://www.ibm.com/developerworks/library/ws-using-oo). 


\section{Advantages of Object-Oriented Analysis and Design}

Encourages Encapsulation: Since everything about OOAD spins around the idea of objects (explicitly, the object-oriented type), one of the greatest advantages of OOAD is that it encourages the planning and creation of systems that are genuinely free of each other. Much the same as a class composed utilizing object-oriented methods, every one of the systems and objects produced amid an OOAD development life cycle can be blended and matched as required, since they will ideally be developed as totally independent elements.

Easy to Understand: Since OOAD standards are on a very basic level dependent on true objects, it's very simple for everybody in the team to rapidly comprehend what an object name means or how a specific behaviour acts. This makes the general development life cycle a much smoother process, especially if your team needs to habitually connect with clients or other non-specialized users about the objects and parts in the system. In such situations, the vast majority still understand how system segments and modeled objects work when they're founded on real life objects and ideas.

\section{Conclusions}

This paper reports the work to be done to develop a DSpace@IMSU repository system, which will be used as a platform for collecting, preserving, and sharing scholarly research outputs at Imo State University (IMSU) as a case study. The development of the system is based on the need for such a system as a solution for the challenges faced by the institution and students in the collection and dissemination of research materials.

The Dspace@IMSU will be implemented using open source DSpace repository software. There are several advantages behind open and free source software. One is overcoming the financial constraints most organizations face in implementing similar systems. The other major advantage is the continued support and improvement that open source software benefits from the global community of software developers. Therefore, the Dspace@IMSU repository is suitable.

The Dspace@IMSU system will also benefit the institution in many other ways. For example, it can be used as a tool to monitor and assess the number and quality of research outputs of the institution. By doing so, the value of money invested in research and educational activities can be evaluated based on this fact. The system also can be a platform for new knowledge discovery which can create innovations that solve other similar challenging problems.

\section{Conflicts of Interest}

The authors declare no conflicts of interest regarding the publication of this paper.

\section{References}

[1] Helen, H.-Y. (2006) Digital Preservation in the Context of Institutional Reposito- 
ries. Program: Electronic Library and Information Systems, 40, 232-243. https://doi.org/10.1108/00330330610681312

[2] Gibbons, S. (2004) Establishing an Institutional Repository. Library Technology Report, 40, 11-14.

[3] Budapest Open Access Initiative. (2002) http://www.soros.org/openaccess/

[4] Chan, L. (2004) Supporting and Enhancing Scholarship in the Digital Age: The Role of Open Access Institutional Repositories. Canadian Journal of Communications, 29, 277-300. https://doi.org/10.22230/cjc.2004v29n3a1455

[5] Lynch, C. and Lippincott, J. (2005) Institutional Repository Deployment in the United States as of Early 2005. D-Lib Magazine, 11, No. 9. https://doi.org/10.1045/september2005-lynch

[6] Van de Sompel, H. and Lagoze, C. (2000) The Santa Fe Convention of the Open Archives Initiative. D-Lib Magazine, 6, No. 2.

https://doi.org/10.1045/february2000-vandesompel-oai

[7] Tansley, R. and Harnad, S. (2000) Eprints.org Software for Creating Institutional and Individual Open Archives. D-Lib Magazine, 6, No. 10.

[8] Harnad, S. (2005) The Implementation of the Berlin Declaration on Open Access. D-Lib Magazine, 11, No. 3. https://doi.org/10.1045/march2005-harnad

[9] Crow, R. (2006) The Case for Institutional Repositories: A SPARC Position Paper Archived 2011-02-04 at the Wayback Machine. Discussion Paper. Scholarly Publication and Academic Resources Coalition, Washington DC.

[10] Lynch, C. (2003) Institutional Repositories: Essential Infrastructure for Scholarship in the Digital Age. ARL Bimonthly Report, 226.

http://www.arl.org/resources/pubs/br/br226/br226ir.shtml

https://doi.org/10.1353/pla.2003.0039 